\title{
Influence of electrical stimulation of the tibialis anterior muscle in paraplegic subjects. 1. Contractile properties
}

\author{
L Rochester $^{1}$, CS Chandler ${ }^{1}$, MA Johnson ${ }^{2}$, RA Sutton ${ }^{4}$ and S Miller ${ }^{3}$ \\ ${ }^{1}$ Institute of Health Sciences, University of Northumbria at Newcastle, NE7 7XA; ${ }^{2}$ Division of Neurobiology and \\ ${ }^{3}$ Department of Child Health, Newcastle upon Tyne University, NE2 4HH; ${ }^{4}$ Regional Spinal Injuries Unit, \\ Hexham General Hospital, NE46 1QJ, UK
}

\begin{abstract}
In adult paraplegic subjects one tibialis anterior muscle received daily electrical stimulation for 4 weeks at twice motor threshold to determine changes of its contractile properties (this paper) and its morphological and histochemical profiles (following paper). ${ }^{1}$ Force, speed of contraction and fatigue resistance were assessed by percutaneous electrical stimulation of the muscle with torque measured about the ankle. Comparative contractile tests were performed on 51 normal adult subjects and new parameters for force measurement proposed, particularly where maximum voluntary contraction cannot be obtained. In paraplegic subjects before stimulation the tibialis anterior muscle showed evidence of disuse with decreased force, faster contraction and relaxation, and reduced fatigue resistance. The effects of two stimulus patterns were compared: $10 \mathrm{~Hz}$, and $10 \mathrm{~Hz}$ with $100 \mathrm{~Hz}$ bursts. After stimulation contraction was slower, fatigue resistance increased and there was a tendency for force to increase. No differences occurred using the different stimulus patterns. Four weeks later fatigue resistance was partially maintained, while speed of contraction reverted to pre-stimulus levels.
\end{abstract}

Keywords: skeletal muscle; contractile properties; electrical stimulation; paraplegic subjects

\section{Introduction}

Restoration of the contractile properties of skeletal muscle is prerequisite for rehabilitation and return to mobility in subjects who have suffered neurological or orthopaedic trauma leading to periods of muscular disuse. The use of electrical stimulation of muscle to restore contractile properties following disuse has advantages of ease of application and can deliver reliably a known amount of exercise without the subject having voluntarily to perform an exercise regime. ${ }^{2}$ This type of therapeutic intervention, at a stage when the patient may be less able to cooperate, is attractive and may prevent or slow down the effects of disuse on contractile properties. ${ }^{3,4}$ The benefit and cost effectiveness of such treatment may be measured in the reduction of rehabilitation necessary at a later stage. ${ }^{5}$ Despite the widespread use of electrical stimulation to restore muscle function in man, the detailed application of the method remains controversial, particularly with regard to the choice of stimulus parameters to produce an optimal or appropriate response. ${ }^{6-9}$

The contractile properties of skeletal muscle fibres are strongly influenced by the activity of the motoneurons which innervate them. ${ }^{10,11}$ In animals muscle properties are altered in a well defined manner following electrical stimulation of the motor nerve (see

Correspondence: S Miller
Reference 2 for review). Prolonged periods of low frequency $(10 \mathrm{~Hz})$ stimulation greater than $50 \%$ of daily time result in a reduction of force and a decrease in muscle fibre diameter. ${ }^{2}$ Prolonged high frequency $(20-40 \mathrm{~Hz})$ stimulation gives a similar result, but the reduction in force is less than that with low frequencies $(5-10 \mathrm{~Hz}) \cdot{ }^{12}$ Stimulation for $50 \%$ or more of daily time represents an intensity of motor unit activity an order of magnitude greater than would underlie the normal motor behaviour of daily living. Kernell et $a l^{13}$ examined in the cat the effect of electrical stimulation of peroneus longus for 4 weeks with a duty cycle of $5.0-5.5 \%$ of daily time, an overall period each day in which mammalian motor units may be expected to be active (rat; $\left.{ }^{14} \operatorname{man}^{15}\right)$. Low-frequency stimulation $(10 \mathrm{~Hz}, 5.0 \%$ daily time $)$ in Kernell's experiments resulted in an increase of fatigue resistance, a decrease in force and a shift to smaller fibre diameters. High frequency $(100 \mathrm{~Hz})$ bursts added to the $10 \mathrm{~Hz}$ background stimulation for $5.5 \%$ daily duty cycle partly compensated for the decrease in force. ${ }^{13}$ Using a somewhat similar approach to muscles of the hand in human subjects, Rutherford and Jones ${ }^{16}$ also provided some evidence that bursts of high frequency stimulation in addition to low frequency stimulation help to maintain force of contraction.

The results of electrical stimulation of muscle in animal experiments are difficult to extrapolate to man 
for the development of therapeutic procedures. Simoneau and Pette ${ }^{17}$ concluded that homologous muscles of different species may react in specific and nonuniform ways to increased activation and noted that although the enzyme activities of oxidative and glycolytic metabolism in various species exhibit the same direction of change with stimulation, the changes differ greatly in magnitude. The parameters of stimulation used in animal experiments cannot therefore be applied indiscriminately in clinical situations, particularly where many patients' muscles have already undergone morphological and histochemical changes in response to disuse. In human subjects, therefore, it is still unclear the extent to which electrical stimulation can actually retrain the contractile properties of skeletal muscle more effectively than voluntary exercise. If electrical stimulation can indeed enhance muscle function by improving fatigue resistance and strength, or delay impaired function resulting from neurological or orthopaedic disorders, the method then has far reaching implications not only for rehabilitation, but for physical education and athletic performance.

The aims of the present study were therefore to characterise the changes in the contractile properties and the morphological and histochemical profiles of the tibialis anterior muscle following a 4 week period of electrical stimulation. This period and the daily duty cycle were chosen corresponding to the period of stimulation used by Kernell et $a l^{13}$ in the cat. Paraplegic subjects who had suffered complete spinal transection at T4-T12 one or more years previous to testing were chosen for study, since their lower limb muscles were disused and could not be activated voluntarily. The experimental paradigm described by Kernell, Donselaar and Eerbeek ${ }^{13}$ in the cat was adopted with the hypothesis that low frequency electrical stimulation of tibialis anterior would evoke fatigue resistance but no increase of force, and that a combination of low and high frequencies would evoke fatigue resistance and maintain force of contraction. Stein et al ${ }^{18,19}$ also used electrical stimulation to retrain tibialis anterior in paraplegic subjects. Their approach, however, differed from the present study in that the period of stimulation was very much longer, the stimulus intensity was maximal and only a $10 \mathrm{~Hz}$ stimulus train was used. This paper describes the changes of contractile properties and the following paper ${ }^{1}$ the morphological and histochemical results. A brief report of the study has been published. ${ }^{20}$

\section{Materials and methods}

\section{Subjects}

The study was performed on a group of seven paraplegic subjects (6 male, aged 19-43 years; 1 female, aged 19 years) with complete thoracic spinal transection, sustained 1-14 years previously (Table 1). Subjects were recruited by letter circulated to 80 paraplegic patients registered at the Regional Spinal Injuries Unit, Hexham General Hospital. The criteria for selection included: complete thoracic spinal transection between
Table 1 Details of paraplegic subjects

\begin{tabular}{lccccccc}
\hline Subject & 1 & 2 & 3 & 4 & 5 & 6 & 7 \\
\hline Sex & M & M & F & M & M & M & M \\
Age & 43 & 29 & 19 & 34 & 39 & 21 & 20 \\
Level of transection & T4 & T5 & T6 & T4 & T12 & T5 & T6 \\
Years after spinal injury & 14 & 6 & 6 & 6 & 12 & 1 & 2 \\
Stimulation pattern used & S & S & SF & SF & S & SF & SF \\
\hline
\end{tabular}

$\mathrm{S}=$ slow pattern $\mathrm{SF}=$ slow/fast pattern

$\mathrm{T} 1$ and T12, determined on clinical assessment by total lack of voluntary motor function and somatic sensation below the level of the lesion; integrity of spinal reflexes in both lower limbs; no previous history of neurological disorder; no incidence of fracture, trauma or contractures of the lower limbs; no previous use of electrical stimulation of muscle prior to study. A group of 51 normal healthy subjects ( 27 male, aged 18-54 years; 24 female, aged 19-55 years) were studied for comparison with the group of paraplegic subjects. The criteria for selection were: no previous incidence of fracture or trauma to the lower limbs; no bone or joint pathology; no neurological disorder; no female subject was pregnant.

Ethical approval for the study was obtained from the Northumberland Health Authority ethical committee. All subjects gave informed, written consent.

\section{Muscle investigated}

The tibialis anterior muscle was selected for its superficial position, allowing ease of stimulation by surface electrodes, recording of the surface electromyogram and biopsy of the muscle. ${ }^{21}$ Furthermore, it develops less force during maximal contraction than, for example, quadriceps femoris, thus minimising the possibility of fractures of limb bones severely weakened by osteoporosis.

\section{Electrical stimulator}

A constant current electrical stimulator (developed and built by the Northern Region Medical Physics Department and conforming to British Standard 5724) was used in tests of contractile properties. It delivered a biphasic pulse ( $400 \mu$ s duration in each phase) with a variable current output in the range of $5-100 \mathrm{~mA}$. Safety features included isolation from earth, automatic electrode impedance measurements before the delivery of each pulse, and automatic cut-off if electrode impedance exceeded $10 \mathrm{k} \Omega$. The current intensity and the timing of the pulses could be set on-line by the computer used for data acquisition. A similar stimulator but with an EPROM containing the stimulus patterns was used by the paraplegic subjects for electrical stimulus training.

\section{Assessment of contractile properties}

The tibialis anterior muscle was stimulated with surface electrodes (Myocare 3M, Ltd, Bracknell, UK), measuring $10 \times 30 \mathrm{~mm}$. The skin was shaved, lightly 
abraded (Omniprep; Weaver \& Co, Aurora, CO 80011, USA) and cleaned with propyl alcohol. The electrodes were attached with Hypafix tape (Smith \& Nephew Medical Ltd, Hull, UK) and positioned with the long side in the vertical anatomical plane. The proximal electrode was placed medial to the head of the fibula and inferior to the lateral tibial condyle. The distal electrode was placed over the midpoint of the muscle belly. In order to ensure the repeatability of electrode placement, a template of transparent acetate sheet was made for each paraplegic subject and used to guide electrode placement on subsequent visits.

\section{Measurement of torque about the ankle joint}

The subjects were seated in a dental examination chair to maintain a standard position during the tests (Figure 1c). The angles of the hip and knee joints were set at $90^{\circ}$. Using a specially designed rig (Figure 1c) measurements of torque about the ankle joint were made to enable the contractile properties of the tibialis anterior muscle to be determined. The ankle joint was maintained at an angle of $10^{\circ}$ of plantar flexion, since at this position the length of the tibialis anterior is optimal for the production of contractile force..$^{22}$ The lower

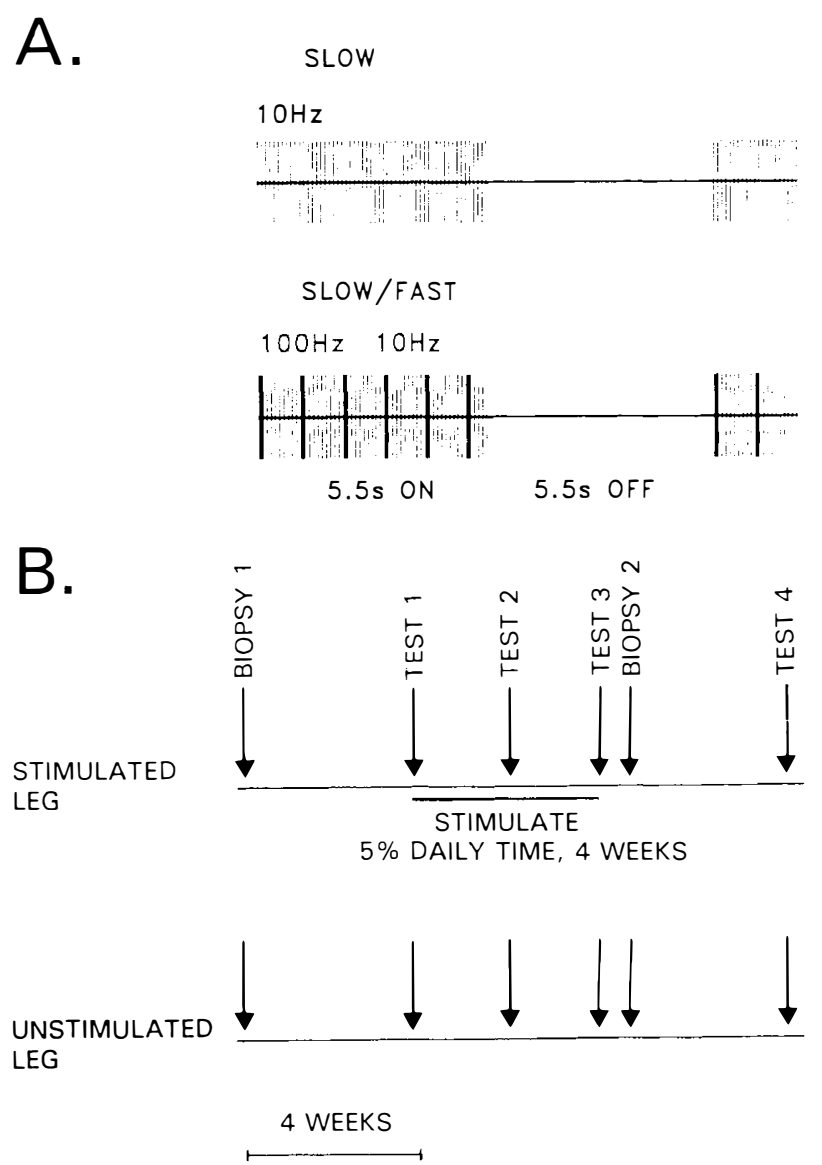

limb was immobilised using a system of clamps, Velcro straps and evacuable bean bags (Figure 1c). When evacuated, the bean bags provided a firm, relatively incompressible medium, against which the Velcro straps acted. The bags were chosen since they moulded to the contours of the subject and distributed the force of the straps equally across the skin. This was considered an important precaution against the development of pressure sores in the paraplegic subjects. On contraction of the tibialis anterior muscle isometric torque was transmitted to a strong, high quality steel beam upon which foil strain gauges were mounted (micro-measurements EA-06-240LZ-120). The beam rested against a steel pin, fixed in position with a clamp, preventing movement of the footplate. The output from the strain gauges was amplified and the signal sampled at a frequency of $1 \mathrm{kHz}$ by a computer system (IBM compatible computer with Cambridge Electronics Design Ltd, Cambridge, UK, type 1401 interface).

\section{Recording of electromyograms (EMGs)}

Surface EMGs were recorded from the tibialis anterior, the peroneus longus and the lateral head of the gastrocnemius muscles to control for the possible

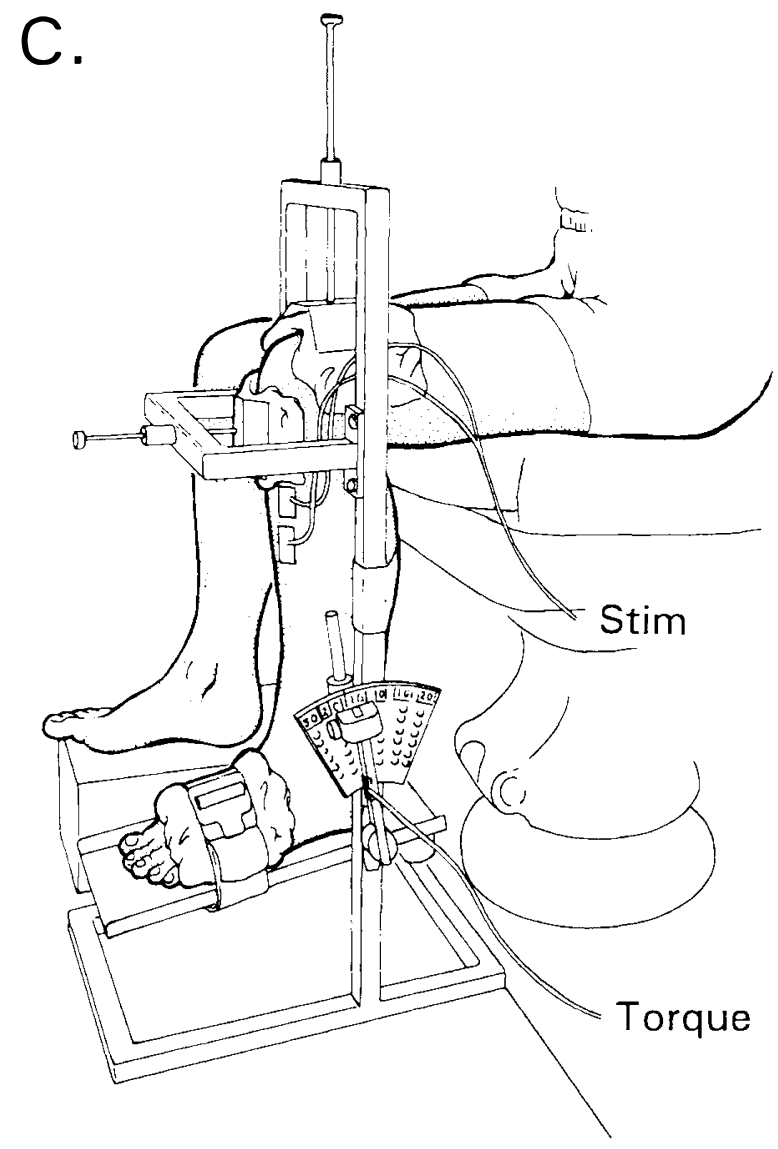

Figure 1 (a) Stimulation patterns (see text). (b) Experimental designs, illustrating the order of tests applied to paraplegic subjects. In each subject, one limb acted as the stimulated limb and underwent a period of training using electrical stimulation, the other limb acted as the control and remained unstimulated. All tests were performed on both limbs. (c) Ankle torque rig used to test contractile muscle properties, showing the position of the limb and methods used to prevent unwanted movement. Stim = electrical stimulus; Torque = output of strain gauges signalling torque at ankle joint 
spread of stimulus current to other muscles and to record any reflex responses. The skin was prepared as described earlier. Recording electrodes (Medelec International, Woking, $\mathrm{UK}, \mathrm{Ag} / \mathrm{AgCl}, 6 \mathrm{~mm}$ diameter, filled with Camjel, Picker International, Wembley, UK) were attached to the skin with double sided adhesive discs, secured with Hypafix tape, at a separation of $20 \mathrm{~mm}$ between centres. The electrodes were placed in the vertical plane over the midpoint of the muscle belly, in the case of the tibialis anterior muscle below the stimulating electrodes. An amplifier with a switchable mute input of $1 \mathrm{~ms}$ was used to minimise the stimulus artefact. ${ }^{23}$ The signals were filtered with a $-3 \mathrm{~dB}$ bandpass of $10-1000 \mathrm{~Hz}$ and sampled at $2 \mathrm{kHz}$.

\section{Stimulus paradigms used to determine contractile properties}

Isometric contractions of the tibialis anterior muscle were elicited using the computer controlled electrical stimulator. For all tests, except the fatigue test, an interval of $12 \mathrm{~s}$ was interposed between the delivery of the single stimulus or brief train of stimuli, to avoid the effects of facilitation or fatigue. The temperature of the environment was maintained at $25^{\circ} \mathrm{C}$ to minimise effects of changes of intramuscular temperature..$^{24}$ The following tests were applied in sequence.

1 Single stimulus test. (a) Single stimuli were delivered in $5 \mathrm{~mA}$ increments over the range $10-100 \mathrm{~mA}$, with three repeats at each amplitude. (b) For determining the threshold of response single stimuli were delivered in $1 \mathrm{~mA}$ increments from a level just below threshold until a response was detected in the torque signal. The level at which contraction was just detected was defined as the threshold $(\mathrm{T})$.

2 Frequency response test. A stimulus train of $500 \mathrm{~ms}$ duration at a current amplitude of $2 \times \mathrm{T}$ (twice threshold) was delivered, with no repeats, in steps of $10 \mathrm{~Hz}$ over the frequency range $10-100 \mathrm{~Hz}$.

3 Tetanic response test. A stimulus train at $40 \mathrm{~Hz}$, duration $500 \mathrm{~ms}$, was delivered in steps of $5 \mathrm{~mA}$ over the range $10-40 \mathrm{~mA}$.

4 Maximum voluntary contraction (normal subjects only). Three maximal voluntary contractions of $3 \mathrm{~s}$ duration were performed in response to an auditory and visual signal, each attempt being separated by $20 \mathrm{~s}$.

5 Fatigue test. A test similar to that of Burke et al ${ }^{25}$ was used, in which stimulus trains at $40 \mathrm{~Hz}, 330 \mathrm{~ms}$ duration, current of $2 \times \mathrm{T}$, were delivered every second for $5 \mathrm{~min}$. To describe the decrease in torque a fatigue index (FI\%) was calculated similar to that of Edwards et $a l^{26}$ and Lenman et al, ${ }^{27}$ giving the percentage of torque remaining after a $3 \mathrm{~min}$ period, as determined by the equation:

$$
\mathrm{FI} \%=\frac{181 \mathrm{~s}}{1 \mathrm{~s}} \times 100
$$

where $1 \mathrm{~s}=$ peak torque at $1 \mathrm{~s}$, and $181 \mathrm{~s}=$ peak torque at $181 \mathrm{~s}$.
A half relaxation time index (HRTI\%) was calculated as the percentage increase in tetanic half relaxation time from $1 \mathrm{~s}$ to $181 \mathrm{~s}$, as described by Lenman et al: ${ }^{27}$

$$
\mathrm{HRTI} \%=\frac{(181 \mathrm{~s}-1 \mathrm{~s})}{1 \mathrm{~s}} \times 100
$$

where $1 \mathrm{~s}=$ half relaxation time at $1 \mathrm{~s}$, and $181 \mathrm{~s}=$ half relaxation time at $181 \mathrm{~s}$.

The following parameters were computed and recorded: peak torque; rise time, measured from 5-95\% peak twitch amplitude or $5-50 \%$ peak tetanic amplitude; half relaxation time, measured from $95-50 \%$ of peak twitch or tetanic amplitude. The ranges of rise time and relaxation time were chosen for measurement to avoid difficulties in determining the baseline and peak values.

In the paraplegic subjects the presence of reflex muscle spasm induced by the stimulus occasionally contaminated the responses. This was reduced (1) by the application prior to stimulation of a topical anaesthetic cream (Emla Cream - a mixture of lignocaine and prilocaine) to the area of skin underlying the electrodes and in some cases (2) anaesthetic block of the common peroneal nerve ( $10 \mathrm{ml}$ of $1 \%$ lignocaine).

\section{Electrical stimulation training}

Two patterns of stimulation were compared, similar to those described by Kernell et al.$^{13}$ Slow pattern (S): a stimulus train of $5.5 \mathrm{~s}$ at $10 \mathrm{~Hz}$ followed by $5.5 \mathrm{~s}$ was repeated. Slow/fast pattern (SF): a stimulus train of $5.5 \mathrm{~s}$ at $10 \mathrm{~Hz}$ with a superimposed $100 \mathrm{~ms}$ train at $100 \mathrm{~Hz}$ occurring at the onset of each second of the $10 \mathrm{~Hz}$ train; a rest period of $5.5 \mathrm{~s}$ then followed (Figure 1a). The paraplegic subjects were divided into two groups, each being randomly assigned to a stimulus pattern, slow pattern (three subjects), slow/fast pattern (four subjects). Over a 4 week period tibialis anterior of one limb (stimulated limb) was stimulated electrically on a daily basis, while the other limb remained unstimulated (unstimulated limb). The electrical stimulation was applied for 4 weeks by the subject at home for $48 \mathrm{~min}$, three times a day, corresponding to $5 \%$ of daily time. The current amplitude was set at twice threshold for muscle contraction, determined from tests of contractile function described above. During stimulation the leg hung down unsupported with the knee flexed to about $90^{\circ}$ and tibialis anterior was allowed to shorten freely without external loading. The subjects kept a diary of the experimental period, noting times of stimulation each day, whether any sessions were missed, the duration and intensity of any muscle spasms in either leg and the condition of skin of the experimental leg.

\section{Sequence of contractile tests and muscle biopsies (Figure 1b)}

Tests of contractile properties were performed on both legs of the normal and paraplegic subjects. The normal subjects were assessed on one occasion only. The 
paraplegic subjects were tested immediately before the period of electrical stimulation training (test 1), following 2 weeks of stimulation (test 2), immediately after the training period (test 3 ) and 4 weeks later (test 4). Biopsies were taken from both tibialis anterior muscles of the paraplegic subjects 4 weeks before the training period and immediately after test 3 . The results of the biopsies are reported in the following paper. ${ }^{1}$

\section{Data analysis}

In normal subjects all variables were tested for the effects of sex and dominance using unpaired and paired $t$ tests. A reference range corresponding to $95 \%$ confidence limits of normal data was calculated from variance within and between subjects using the method described by Armitage and Berry. ${ }^{28}$ In paraplegic subjects, where sufficient numbers of observations were available, the data from the paraplegic subjects were pooled for comparison with the data of the normal subjects, using unpaired $t$ tests.

\section{Results}

\section{Speed of contraction}

The rise time and half relaxation time of ankle torque in response to electrical stimulation of tibialis anterior were measured from the raw data of single twitch and tetanic contractions (Figure 2). The mean values, obtained from three responses in the range of two to three times the motor threshold $(\times T)$ for the experimental and control legs of the paraplegic subjects, are shown in Figure 3 in relation to the data from normal subjects. This range of current fell below the level (generally $4-6 \times \mathrm{T}$ ) at which recruitment of the pero-

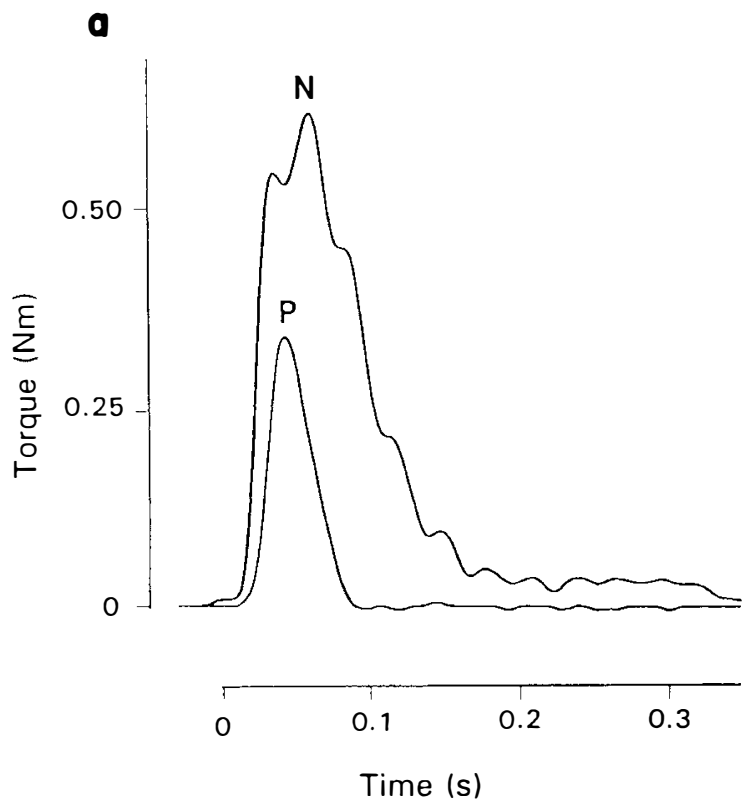

neus longus or the triceps surae muscles occurred and the stimulus was therefore restricted to the tibialis anterior muscle. The possibility of current spread to other muscles of the anterior compartment, the extensor digitorum longus and the extensor hallucis longus, could not be excluded, although palpation and visual inspection of the tendons would suggest that this was unlikely.

Before electrical stimulation training, the rise time of a twitch and tetanic contraction in the paraplegic subjects was shorter than in the normal subject group (Figure 3a, b). In contrast, the values for half relaxation time before the training period were widely scattered both below and above the values of normal subjects (Figure 3c, d). The values of rise time and half relaxation time did not relate to the period of time elapsed between the original spinal lesion (1-14 years) and the first physiological test.

Following electrical stimulation training the rise time and half relaxation time of a tetanic contraction increased in the experimental limbs of the paraplegic subjects (see results of test 1 and test 3 in Figure $3 b, d$ ). In the control limbs these values showed no differences between tests 1 and 3 . These observations indicate that electrical stimulation training over a 4 week period with a duty cycle of $5 \%$ of daily time can result in a slowing of muscle contraction. Both stimulus patterns were effective in prolonging the tetanic half rise and half relaxation time (Figures $3 \mathrm{~b}, \mathrm{~d}$ ). In the single stimulus response test the differences of rise time are very small (Figure 3a), but the half relaxation time tends to be prolonged (Figure 3c). Tetanic contractions may therefore provide a sensitive indicator of changes in the time course of contraction following a period of training with electrical stimulation. The active state is rarely fully attained in a mammalian muscle during a twitch

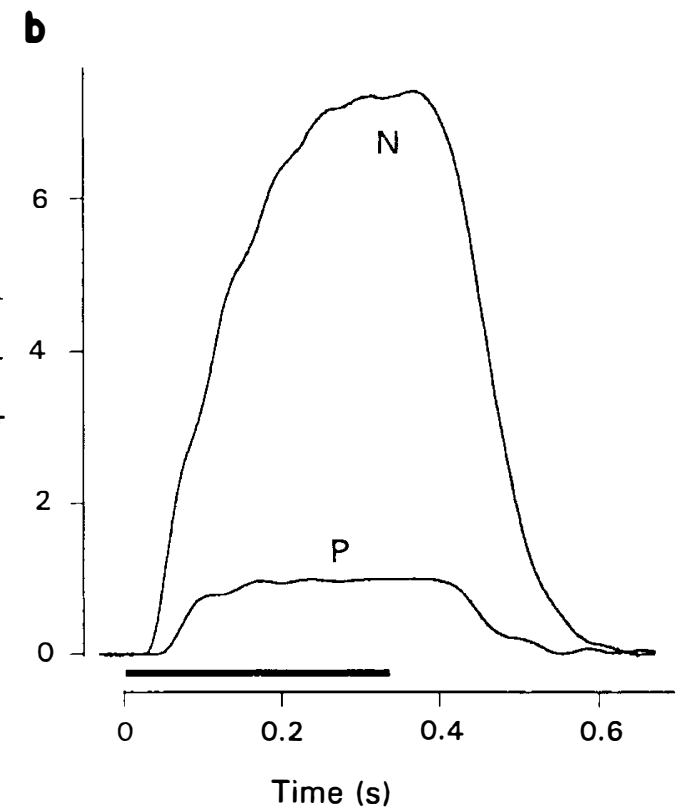

Figure 2 Raw data recorded at a current amplitude of $2 \times \mathrm{T}$. (a) Single stimulus response test. (b) Tetanic response test, the frequency of stimulation is $40 \mathrm{~Hz}$. The horizontal bar shows the duration of the stimulus. $\mathrm{N}=$ normal subject; $\mathrm{P}=$ paraplegic subject. In (a) and (b) the stimulus begins at time zero 

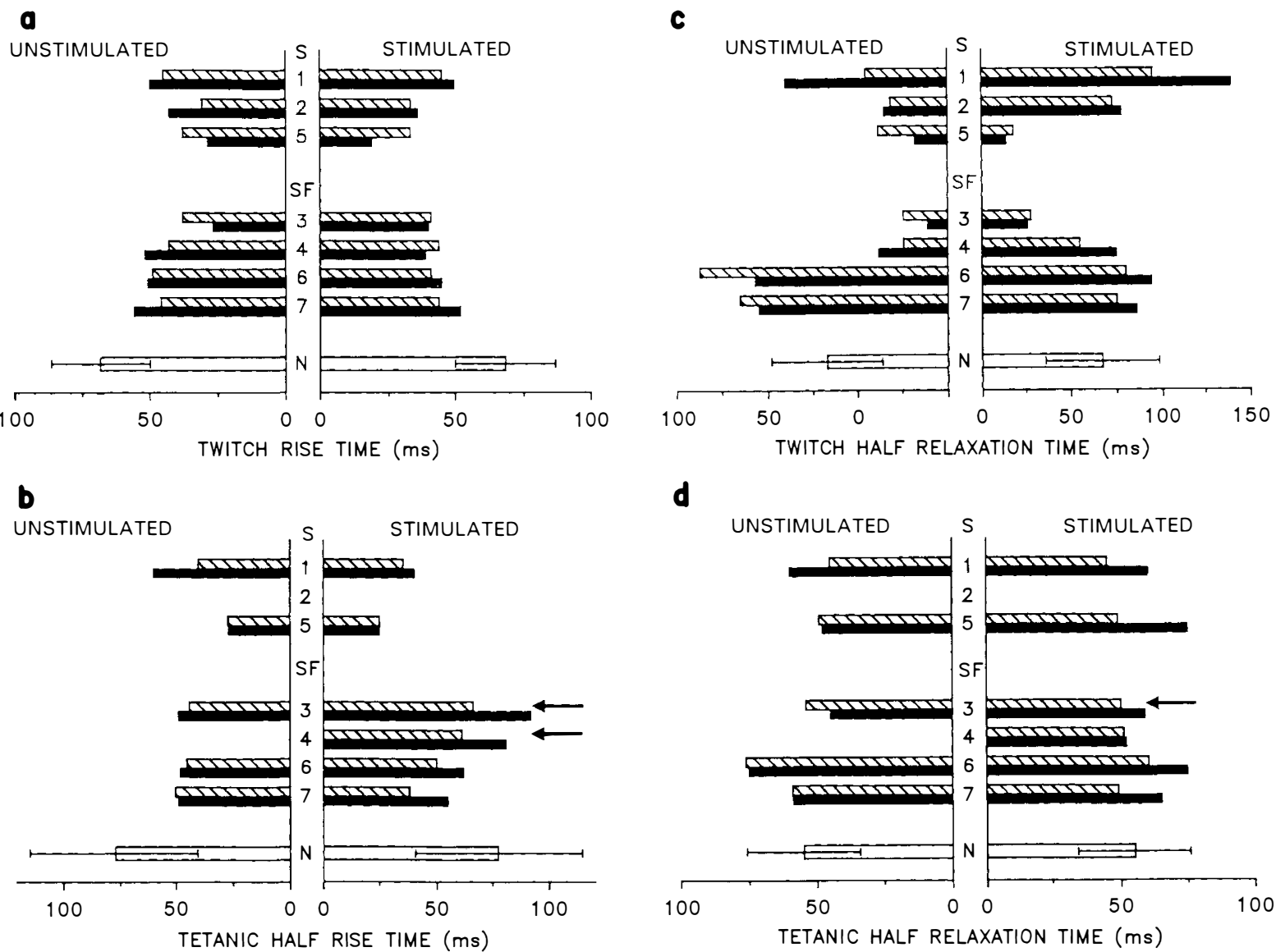

Figure 3 Rise time ( $a$ and b) and half relaxation time (c and d) of twitch and tetanic contraction in stimulated and unstimulated limbs of paraplegic subjects before and after the stimulation period. Hatched and solid bars indicate tests 1 and 3 , respectively. The pattern of stimulation is shown above subject groups $(\mathrm{S}=$ slow pattern; $\mathrm{SF}=$ slow $/$ fast pattern $)$. Subjects are numbered. Missing data are due to spasms whilst testing. Arrows indicate that test 2 data have been substituted where data are missing for test 1 . Normal subjects are shown for comparison, open bar indicating mean and $95 \%$ reference range, illustrated by $\mathrm{N}$

contraction. ${ }^{29}$ Drachman and Johnston ${ }^{30}$ proposed that the use of the tetanic half-rise and half-relaxation times provided a more accurate index of the time course of these parameters than the isometric twitch, on the basis that time was allowed for the active state to be fully developed.

\section{Methods for estimating twitch and tetanic torque}

There are two major difficulties in estimating the maximal force output of a single muscle in the limb. These are due to pain on maximal stimulation, for subjects with intact sensation and to current spread to agonist of antagonist muscle groups at high intensities of current. To overcome these problems the force of contraction of the tibialis anterior muscle was estimated indirectly from the relationship between mean peak torque and current. In a typical subject the relationship is linear from threshold current to approximately $30 \mathrm{~mA}$, corresponding to $2-3 \times \mathrm{T}$ (Figure $4 \mathrm{a}$ ). Thus for each limb the mean peak torque was plotted against current, ranging from threshold to $60 \mathrm{~mA}$. The slope of the straight portion of the relationship was computed, to give the parameter $b_{t w}$ (Figure $4 a$ ). The slope describes the increase in torque, ie the additional proportion of the muscle recruited in the contraction, with increase in current. Data from different subjects were normalised by multiplying $b_{t w}$ with the threshold current value to give the parameter $\mathrm{B}_{\mathrm{tw}}$. This parameter expresses the change in torque with each multiple of threshold, the greater the value of $B_{t w}$, the greater the rate of development of torque with each increment of threshold current. The relationship of peak torque to current in the tetanic response was derived in a similar manner to give the parameters $b_{\text {tet }}$ and $B_{\text {tet }}$. Parameters $B_{t w}$ and $B_{t e t}$ therefore provide normalised estimates of force development in the muscle and are significantly correlated in normal subjects $\left(r^{2}=0.21, P=0.001\right)$.

\section{Frequency response}

Analysis of the relationship between frequency of stimulation and rate of development of torque gave an estimate of torque and the rate of torque development. The peak torque at each frequency was plotted and an exponential curve fitted to these data points, providing 

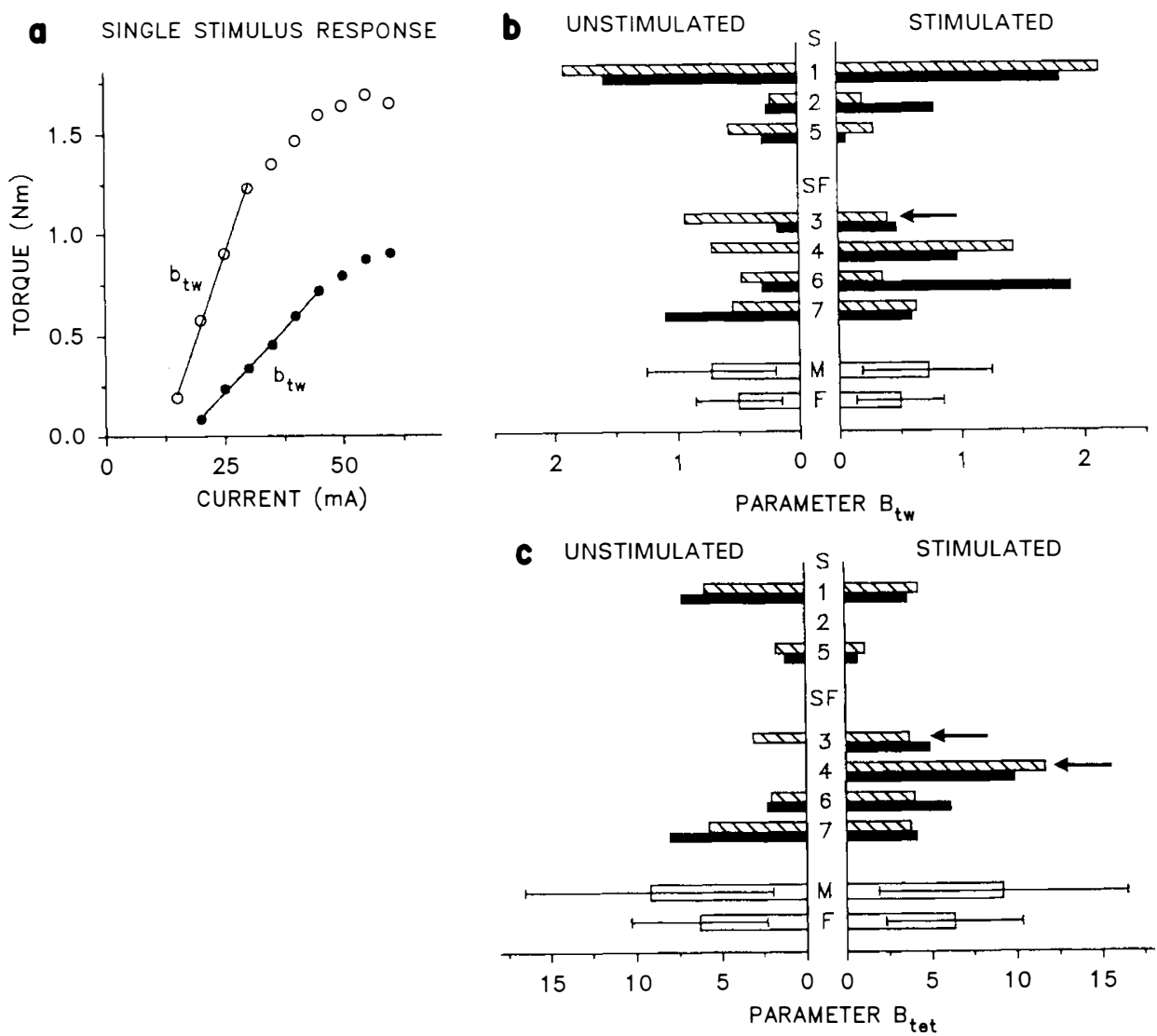

Figure 4 (a) Estimation of torque in single stimulus response test. Torque versus current in one limb of a typical normal ( $\bigcirc)$ and paraplegic (O) subject. Linear regression analysis gave values for the gradient of the slope $b_{t w}$ determined from the equation

$$
\mathrm{T}=\mathrm{b}_{\mathrm{tw}} \times \mathrm{I}+\mathrm{a}
$$

where $\mathrm{T}=$ torque, $\mathrm{b}_{\mathrm{tw}}=$ slope of line, $\mathrm{I}=$ current $(\mathrm{mA}), \mathrm{a}=$ zero intercept, torque where current is zero (not illustrated). (b) and (c) parameters $B_{t w}$ and $B_{t e t}$ (the values of $b_{t w}$ and $b_{t e t}$ normalised by dividing the threshold current) are shown for the stimulated and unstimulated limbs of paraplegic subjects before and after the stimulation period. Hatched and solid bars indicate Tests 1 and 3 , respectively. The pattern of stimulation is shown above subject groups $(\mathrm{S}=\mathrm{slow}$ pattern; $\mathrm{SF}=$ slow/fast pattern). Subjects are numbered. Missing data are due to spasms during testing. Arrows indicate that Test 2 data have been substituted where data are missing for Test 1 . Normal male and female subjects are shown for comparison, open bars indicating mean and $95 \%$ reference range, shown by $\mathrm{M}=$ male and $\mathrm{F}=$ female

two values which summarised the data for each limb as parameters C and D (Figure 5a).

Parameter $\mathrm{C}$ was defined as the asymptote to the curve. Parameter $\mathrm{C}$ is measured at frequencies well above the fusion frequency and therefore provides a further estimate of maximum force output. Regression analysis showed a significant relationship between parameter $\mathrm{C}$ and parameter $\mathrm{B}_{\text {tet }}\left(r^{2}=0.052\right.$, $P=0.05)$. Parameter D, defined as the rate of rise of the curve to peak amplitude, describes the relationship between stimulus rate and torque for each limb. It provides an assessment of the relative amounts of torque developed at different frequencies. A slow twitch muscle will result in a greater development of tension at low frequencies than a fast twitch muscle. ${ }^{31}$ The rate of rise of the curve will be greater if relatively more torque were generated between $10-20 \mathrm{~Hz}$ than $30-40 \mathrm{~Hz}$. Thus if the steep region of the curve occurred at lower frequencies, the value for parameter
$\mathrm{D}$ would be greater. In normal subjects a significant relationship was in fact obtained between parameter $D$ and more conventional measures of contraction time (tetanic half rise time, $r^{2}=0.067, P=0.024$; tetanic half relaxation time, $r^{2}=0.052, P=0.045$ ).

\section{Torque}

In the paraplegic subjects prior to the period of electrical stimulation the tibialis anterior muscle was less able to generate torque than in normal subjects, shown by the parameter $B_{\text {tet }}$ in the tetanic test and parameter $\mathrm{C}$ in the frequency response test (Figure 4c, $5 b)$. The tests with a single stimulus gave unclear results (Figure $4 b$ ). Parameters $B_{\text {tet }}$ and $C$ suggest a possible increase in the force of contraction of the tibialis anterior muscle following 4 weeks' stimulation, even though parameter $\mathrm{C}$ is still significantly different from that of normal subjects (unpaired $t$ test, $P=0.01$ ) 

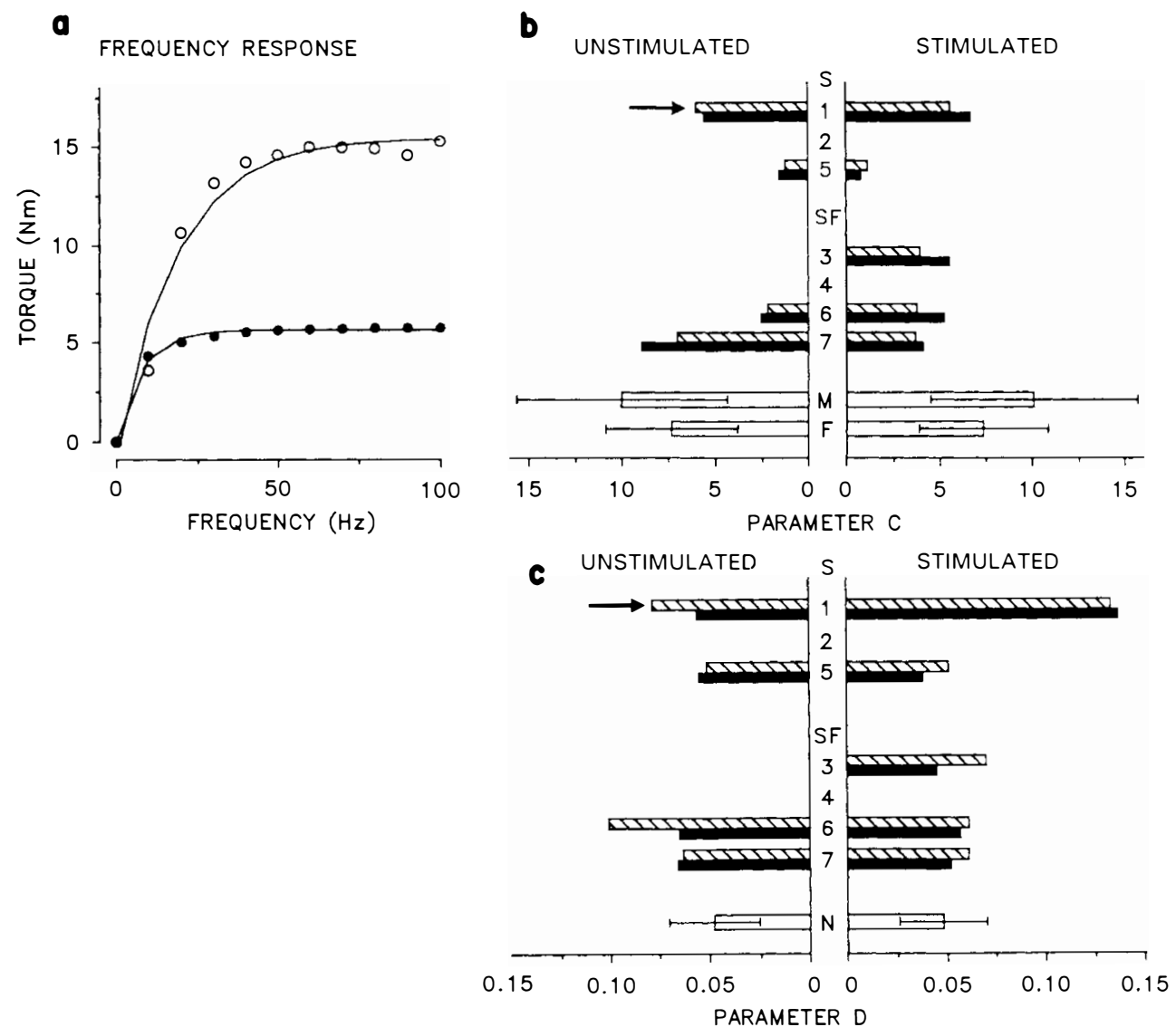

Figure 5 (a) Method of data analysis in frequency response test. Torque versus frequency in a typical normal ( $\bigcirc)$ and paraplegic subject $(\mathbf{O})$, to provide examples of the derivation of the peak amplitude of contraction, parameter $\mathrm{C}$, and the rate of rise of the curve, parameter $\mathrm{D}$. The values were determined using the equation

$$
\mathrm{T}=\mathrm{C}\left(1-\mathrm{e}^{-\mathrm{Df}}\right) \text {, }
$$

where $\mathrm{C}=$ peak amplitude of curve, $\mathrm{D}=$ rate of rise of curve, $\mathrm{f}=$ frequency, $\mathrm{T}=$ torque. (b) and (c) Parameters $\mathrm{C}$ and $\mathrm{D}$ in stimulated and unstimulated limbs of paraplegic subjects before and after the stimulation period. Hatched and solid bars indicate Tests 1 and 3, respectively. The pattern of stimulation is shown above subject groups $(S=$ slow pattern; SF $=$ slow/fast pattern). Subjects are numbered. Missing data are due to spasms during testing. Arrows indicate that Test 2 data have been substituted where data are missing for Test 1 . Normal subjects are shown for comparison, open bar indicating mean and $95 \%$ reference range, $\mathrm{N}=$ normal; $\mathrm{M}=$ male; $\mathrm{F}=$ female

(Figure $4 c, 5 b$ ). The results from the single stimulus response test gave no indication of any change in force of contraction of the tibialis anterior muscle (Figure $4 b$ ). No specific training effects could be attributed to the pattern of stimulation used.

\section{Parameter $D$}

In paraplegic subjects prior to the period of electrical stimulation, parameter $\mathrm{D}$ was generally greater than the mean value of $\mathrm{D}$ in normal subjects (Figure $5 \mathrm{c}$ ). This is a surprising result which conflicts with the values obtained for rise time during twitch and tetanic contraction. Muscles with a faster contraction time would be expected to have a slower rate of torque development at lower frequencies and therefore a smaller value of $\mathrm{D}$. Following training parameter $\mathrm{D}$ decreased in value, to become not significantly different from the normal subjects (unpaired $t$ test,
$P=0.39$ ). A decrease in parameter $\mathrm{D}$ is in conflict with the results recorded for tetanic half rise and half relaxation time, which show a slower time course (Figure 3b, d). No specific training effect was seen with regard to the stimulation pattern applied.

\section{Fatigue}

The graph of percentage decrease in torque with time shows a pattern of change typical of all subjects (Figure 6a), the muscle fatigues rapidly reaching a plateau at approximately $3 \mathrm{~min}$ with relatively little further change in torque.

Prior to training with electrical stimulation the fatigue index (FI\%, see Methods) in the paraplegic subjects was considerably lower than that of the normal subjects indicating a more fatiguable muscle (Figure $6 \mathrm{~b})$. Following training there was a significant increase in fatigue resistance in the paraplegic subjects (paired 


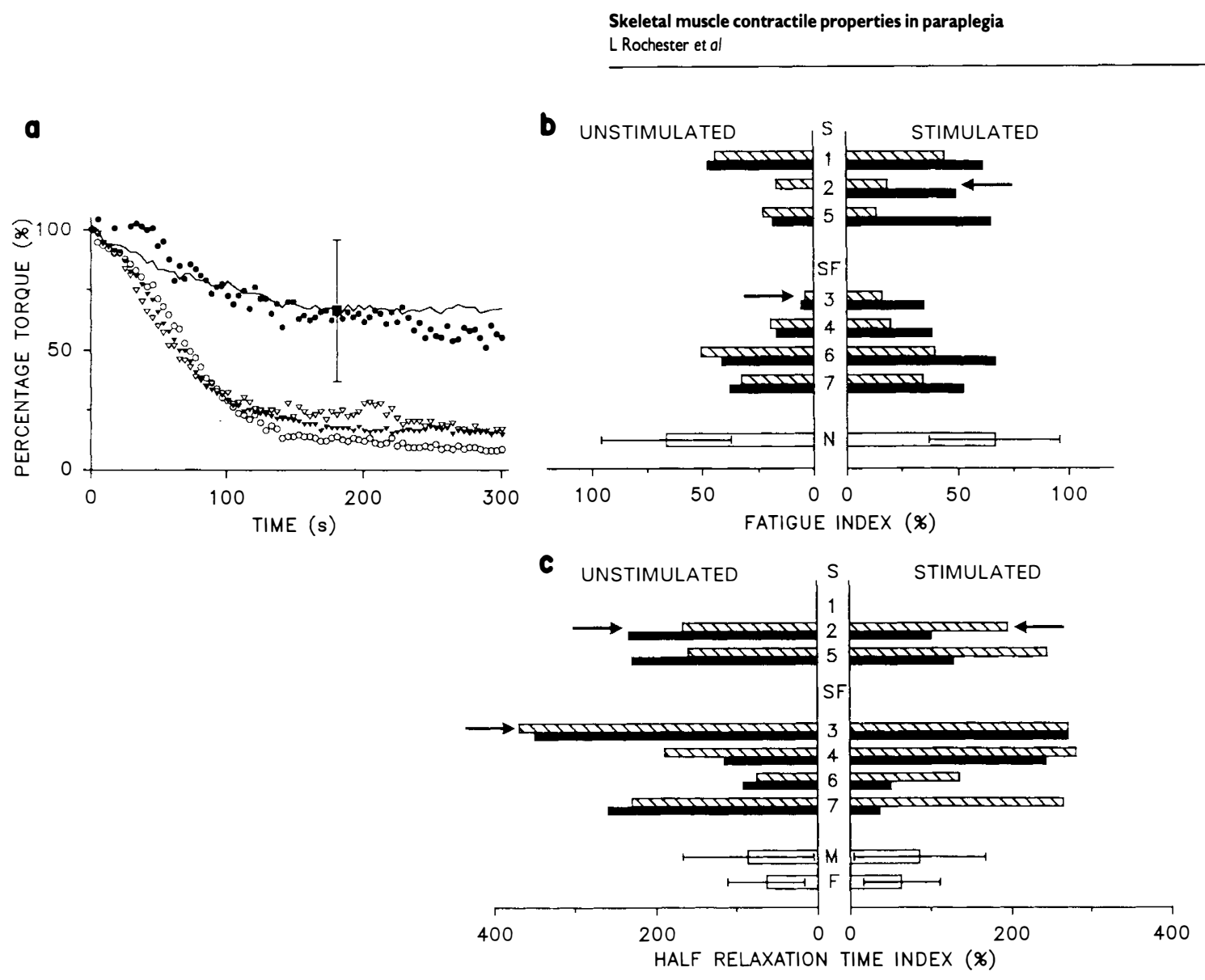

Figure 6 (a) Torque versus time during fatigue test. Each data point is a percentage of the initial value at $1 \mathrm{~s}$. Responses are recorded at $4 \mathrm{~s}$ intervals during the test at a current amplitude of $2 \times \mathrm{T}$. Solid line gives the fatigue curve of a typical normal subject. The solid square $\square$ and error bars at $180 \mathrm{~s}$ indicate the mean and $95 \%$ reference range obtained from the complete group of normal subjects. The remaining data symbols are defined as follows: $\bigcirc$ and $\bigcirc$, Tests 1 and 3 stimulated limb of typical paraplegic subject; $\nabla$ and $\boldsymbol{\nabla}$, Tests 1 and 3 in unstimulated limb of same paraplegic subject. (b) and (c) fatigue index and half relaxation time index in stimulated and unstimulated limbs of paraplegic subjects before and after the stimulation period. Hatched and solid bars indicate Tests 1 and 3, respectively. The pattern of stimulation is shown above subject groups. $(\mathrm{S}=$ slow pattern; $\mathrm{SF}=$ slow/fast pattern). Subjects are numbered. Missing data are due to spasms whilst testing. Arrows indicate that Test 2 data have been substituted where data are missing for Test 1 . Normal subjects are shown for comparison, open bar indicating mean and $95 \%$ reference range, $\mathrm{N}=$ normal; $\mathrm{M}=$ male; $\mathrm{F}=$ female

$t$ test, $P=0.0049)$, while no significant increase was seen in unstimulated limbs (paired $t$ test, $P=0.49$ ) (Figure 6b). No specific training effects were observed relating to the pattern of stimulation used. While the fatigue index approached values for the normal subjects, it still remained significantly different from this group (unpaired $t$ test, $P=0.019$ ). A significant difference also remained between the unstimulated limbs of the paraplegics and those of normal subjects (unpaired $t$ test, $P=0.0023$ ). The changes seen in the stimulated limbs can be attributed to the training regime. Subject 4 demonstrated an initial increase followed by a decrease and this may have been due to muscle damage, which was evident in the second biopsy taken immediately after the training period. Thus the fatigue test may provide a useful indicator of muscle damage occurring during a muscle training programme.

\section{Rate of relaxation}

The half relaxation time $(95-50 \%)$ for each tetanus was analysed for all limbs and showed a progressive increase during the fatigue test. Prior to the period of electrical stimulation, the paraplegic subjects demonstrated a greater slowing of rate of relaxation during the fatigue test and thus a larger half relaxation time index (HRTI\%, see methods) compared to the normal subject group (Figure 6c). Following electrical stimulation training, however, the paraplegic subjects showed no significant difference to the normal subjects following training (unpaired $t$ test, $P=0.17$ ) whilst the control limbs remained significantly different (unpaired $t$ test, $P=0.017)$. Electrical stimulation therefore resulted in a decrease in the half relaxation time index to normal values. No specific effect was measured between the stimulation patterns.

\section{Detraining of the tibialis anterior muscle}

The half rise time and half relaxation time of a tetanic contraction reverted back to pre-stimulation levels 4 weeks after cessation of electrical stimulation (Figure $7 \mathrm{a}, \mathrm{b})$. Fatigue resistance, however, appeared to be partially maintained (Figure 7c). No clear trends were recorded for the other parameters measured. 

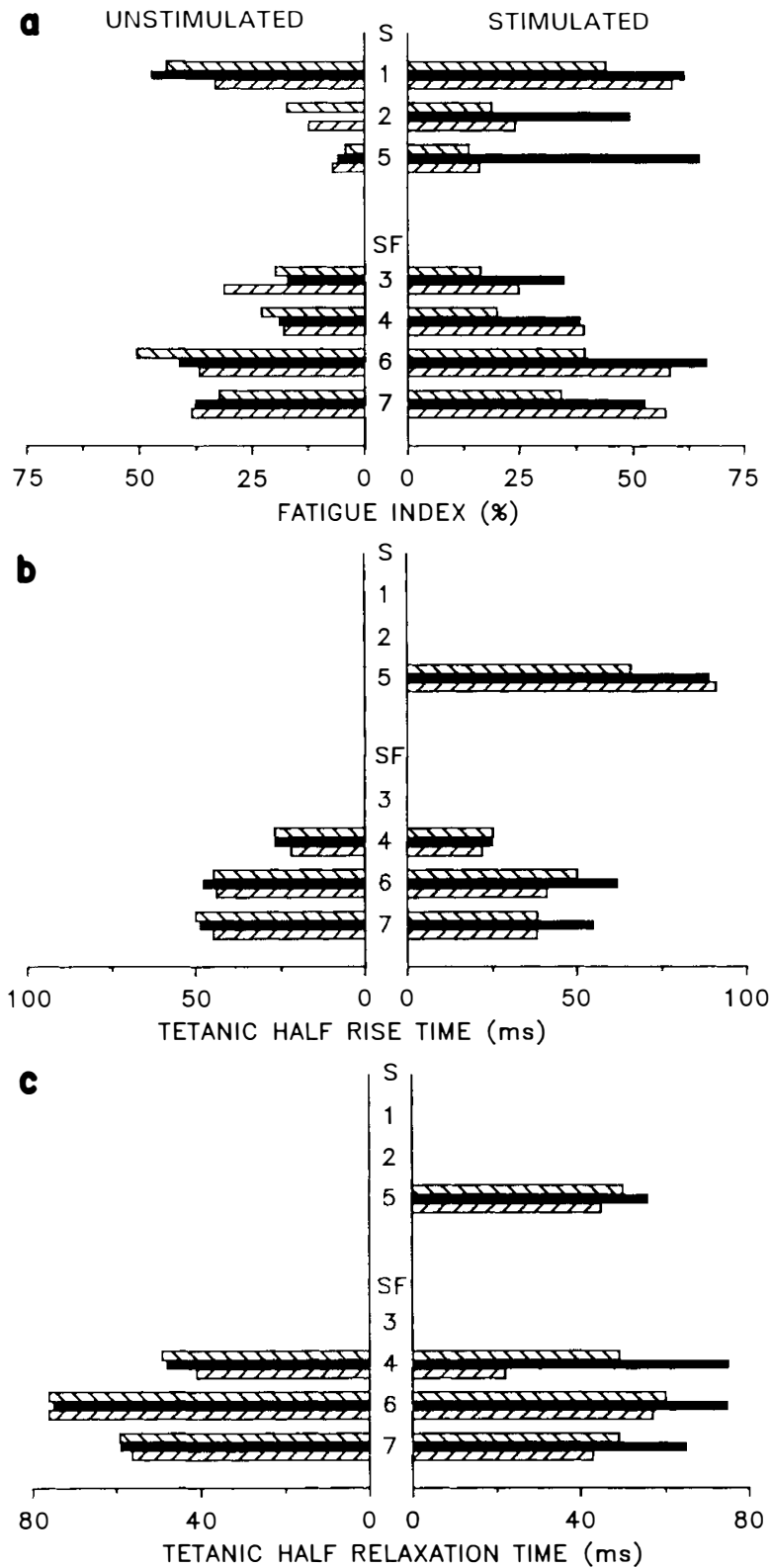

Figure 7 The effects of detraining in stimulated and unstimulated limbs of paraplegic subjects before and after the stimulation period. (a) Fatigue index. (b) Tetanic half rise time. (c) Tetanic half relaxation time. For each subject three histograms are presented for the unstimulated and stimulated leg. The upper hatched bar, the central solid bar and the lower hatched bar refer to the results of Tests 1,3 and 4 , respectively. The pattern of stimulation is shown above subject groups $(\mathrm{S}=$ slow pattern; $\mathrm{SF}=$ slow/fast pattern). Subjects are numbered. Missing data are due to spasms whilst testing

\section{Discussion}

This study describes in detail the changes occurring in the tibialis anterior muscle in human subjects following disuse and subsequent training with a 4 week period of electrical stimulation and provides information on the carry-over of the effects of muscle training.
New parameters for determining contractile force and rate of contraction

Estimation of peak torque generated by a single muscle is difficult to obtain, because the high electrical currents required will excite neighbouring muscles and, in subjects with intact sensation, may evoke unbearable pain. Normalising the applied suprathreshold stimulating currents by reference to the threshold current value carries an implicit assumption that comparable increments of threshold current excite a comparable increase between subjects in the number of active motor units or muscle fibres. If the assumption is accepted, the parameters $\mathrm{B}_{\mathrm{tw}}$ and $\mathrm{B}_{\text {tet }}$, derived from responses in the single stimulus and tetanic tests, represent a novel method for the analysis of force development in a single muscle. Larger values of $\mathrm{B}_{\mathrm{tw}}$ and $\mathrm{B}_{\text {tet }}$ would therefore suggest that the muscle fibres recruited with each normalised current increment produce proportionately greater torque at the ankle joint. The parameters thus provide an alternative to estimations of peak force in situations which may be subject to inconsistencies such as the unwanted recruitment of agonist or antagonist muscle groups.

In the frequency response test, performed at a current level of $2 \times \mathrm{T}$, two further new parameters, $\mathrm{C}$ and $\mathrm{D}$, were introduced. Parameter $\mathrm{C}$ was significantly related to the parameters $B_{t w}$ and $B_{t e t}$, describing the development of force, and provides indirect support for the assumption above that equal increments of normalised current evoke comparable increases in torque about the ankle and thus contractile force. Parameter D was significantly related to tetanic rise time and tetanic half relaxation time and it therefore contributes a measure of the speed of contraction.

\section{Changes in contractile properties following disuse}

Following disuse after complete spinal transection the tibialis anterior muscle contracted faster, developed less force and was more fatiguable than in normal subjects. In agreement with Lenman et $a l^{27}$ the halfrelaxation time became slower with repeated tetanic stimulation during the fatigue test. The results of the present study support and extend the observations of other studies in human subjects. ${ }^{27,32}$ Furthermore, the contractile properties appear to be well matched to the histochemical profiles determined from muscle biopsy, with an increase in the proportion of type 2 fibres, a decrease in fibre diameter and a decrease in the activity of oxidative enzymes, as discussed in the following paper. ${ }^{1}$

The paraplegic subjects demonstrated a marked increase in the half relaxation time index in comparison to normal subjects. Lenman et $a l^{27}$ reported similar findings and to a lesser extent in subjects with multiple sclerosis. An increase in half-relaxation time is a characteristic feature of fatigue. Slowing of relaxation is attributed to impairment of calcium uptake by the sarcoplasmic reticulum, or delayed dissociation of cross bridges.$^{33}$ Disuse may further impair the ability to sequester calcium and some suggestion of this process is evident in the present study from the prolonged 
relaxation phase of a tetanic contraction. In addition, Hultman et $a l^{33}$ proposed that relaxation may be regarded as an indirect measure of the energy status of the muscle. Decreased availability of energy required to drive the calcium ATPase pump located in the sarcoplasmic reticulum and for dissociation of cross bridges may result in further slowing of relaxation. There is a decrease in succinate dehydrogenase activity following spinal cord transection, suggesting that the capacity for oxidative metabolism is reduced. ${ }^{1}$ The supply of energy for the processes of relaxation will therefore be less efficient.

The period between the spinal cord lesion and the first physiological test ranged from 1 to 4 years. If the activity of the motoneuron determines the phenotypic properties of the muscle fibres of the motor unit ${ }^{10,11}$ the degree of change of contractile properties would vary with the duration of this period. However, the results show that this is not the case. Factors other than motoneuron activity may thus be responsible for maintaining the properties of the tibialis anterior muscle. $^{34-36}$

\section{Influence of electrical stimulation on contractile properties}

Following a 4 week period of training with electrical stimulation, the contractile properties of the tibialis anterior muscle reverted towards normal values, so that the muscle became slower contracting and more fatigue resistant. Stein et al ${ }^{18,19}$ reported a somewhat similar study of the contractile properties of the tibialis anterior muscle in subjects with low cervical and high thoracic transections. Their study differed in that electrical stimulation was set at a level to produce maximal ankle dorsiflexion, compared to the much lower level of twice motor threshold used in the present study. The stimulation periods were also longer, lasting up to 30 weeks. The authors concluded that this stimulus regime produced, as in the present study, a slowing of the speed of contraction and an increase in fatigue resistance, but little or no change in force production. The duty cycle and the optimal daily stimulation period both corresponded closely to those used in this study. However, it should be noted that in the present study the much lower stimulus currents applied over only a 4 week period produced comparable changes in the contractile properties of the tibialis anterior muscle. This is an important observation for therapeutic application, particularly in view of muscle damage which can accompany periods of electrical stimulation. However, it is encouraging that even after 14 years' disuse the muscle can still adapt to the contractile requirements specified by the discharge of its motoneurons or their axons.

Following electrical stimulation there was a trend towards improved tetanic force (parameters $B_{\text {tet }}$ and C), although the values still remained significantly different from those of the normal subjects. No differences in the development of force were observed with the patterns of stimulation applied, in contrast to the studies in the cat by Kernell et al, ${ }^{13}$ in which maintenance of force was achieved with the injection of bursts of $100 \mathrm{~Hz}$ within the $10 \mathrm{~Hz}$ base frequency. While the same stimulus pattern was applied to the tibialis anterior muscle in the present study, it is not certain how far the muscle fibres may have responded to the $100 \mathrm{~Hz}$ bursts. ${ }^{37}$

Kernell $e t a l^{13}$ performed their study on the peroneus longus muscle, which was initially normal, though paralysed by spinal cord transection and deafferentation. In the present study of paraplegic subjects the tibialis anterior muscle showed physiological and morphological characteristics of prolonged disuse, so that the starting conditions of the muscles prior to electrical stimulation were different. The behavioural conditions in each study during the period of electrical stimulation were also different: the cats were freely moving and weight bearing on the stimulated hindlimb, while the ankle joints of the paraplegic subjects were unloaded.

In man the experimental conditions under which muscles are stimulated can have a profound influence on the extent to which the force of contraction is increased. In the studies of Peckham et al ${ }^{38}$ in tetraplegic subjects and Munsat $e t a l^{39}$ in subjects with upper motor neuron lesions, increases in force and fibre diameter were obtained with contractions which were effectively isometric. Furthermore, Munsat et $a l^{39}$ reported that one subject in whom the contractions were isotonic (no resistance) showed a decrease in fibre diameter. Jones et al ${ }^{40}$ stated that isometric or eccentric contractions are more effective in increasing force and fibre diameter than isotronic contractions. In the present study the ankle joint was freely moving and no load was imposed during training. If the ankle had been constrained so that stimulation produced an isometric contraction it is likely that the development of contractile force would have been more marked.

In a study of muscles of the hand in normal human subjects, Rutherford and Jones ${ }^{16}$ compared the effects on contractile properties using low and high frequency patterns of chronic electrical stimulation. In agreement with the present results, they reported small increases in tetanic half-relaxation time for both patterns of stimulation, while no change in the twitch response was observed. As in the present study Rutherford and Jones observed no differences in fatigue resistance with the different stimulation patterns and this concurs with Kernell's studies in the cat. ${ }^{12,41}$

In agreement with Lenman et al,${ }^{27}$ the half relaxation time index (HRTI\%) returned to normal values following 4 weeks of training, suggesting an improvement in the membrane properties of the sarcoplasmic reticulum to accumulate calcium and a faster dissociation of cross bridges (possibly as a result of improved energy metabolism following training). There is also the possibility that actively respiring mitochondria can store calcium, with the implication that the increased density of mitochondria, observed following electrical stimulation, may act as a buffer for calcium, facilitating its removal from the interior of the cell. ${ }^{42}$ 


\section{Changes of contractile properties 4 weeks after discontinuation of stimulation}

The length of time for which contractile properties are maintained following electrical stimulation is of great significance in the application of the technique of electrical stimulation in rehabilitation. There are few other reports of the carry-over effect of training with electrical stimulation. In the present study, the contraction time of the tibialis anterior muscle reverted to pre-training values following discontinuation of stimulation, in contrast to fatigue resistance which was partially maintained. As a whole the results are comparable to those of Kernell ${ }^{43}$ in the cat and Brown ${ }^{44}$ in the rabbit, but disagree with those of Edwards ${ }^{26}$ in human subjects, who observed a return to pre-training levels after 3 weeks.

Brown et $\mathrm{al}^{44}$ suggested that the time course of change may be on a first-in, last-out basis, implying that those characteristics which adapt most easily to increased activity, eg fatigue resistance, also appear to be the most resistant to change following discontinuation of stimulation. In addition, the time course of change of fatigue resistance appeared to follow that of oxidative enzymes and capillary supply. As a further biopsy was not repeated 4 weeks after stimulation had ended, the activity of SDH could not be assessed.

\section{Acknowledgements}

We acknowledge with gratitude financial support from the Northern Regional Health Authority, Dame Catherine Cookson and the Regional Spinal Injuries Unit Consultants' Trust fund, Hexham General Hospital. We would like to thank Professor Daniel Kernell for helpful discussions in the initiation of the project and Dr John Matthews for statistical advice.

\section{References}

1 Rochester $\mathrm{L}$ et al. Influence of electrical stimulation on the tibialis anterior muscle in paraplegic subjects. 2. Morphological and histochemical properties. Paraplegia 1995; (in press).

2 Salmons S, Henriksson J. The adaptive response of skeletal muscle to increased use. Muscle Nerve 1981; 4: 94-105.

3 Eriksson E, Häggmark T. Comparison of isometric muscle training and electrical stimulation supplementing isometric muscle training in the recovery after major knee ligament surgery. Am J Sports Med 1979; 7: 169-171.

4 Gibson JNA, Smith K, Rennie MJ. Prevention of disuse muscle atrophy by means of electrical stimulation: maintenance of protein synthesis. Lancet 1988; Oct: 767-770.

5 Gould N, Donnermeyer D, Pope M, Ashikaga T. Transcutaneous muscle stimulation as a method to retard disuse atrophy. Clin Orthop 1982; 164: 215-220.

6 Lieber RL. Skeletal muscle adaptability, III: Muscle properties following chronic electrical stimulation. Dev Med Child Neurol 1986; 28: 662-670.

7 Lloyd T, De Domenico G, Strauss GR, Singer K. A review of the use of electromotor stimulation in human muscles. Aus $J$ Physiother 1986; 32: 18-29.

8 Stokes M, Cooper R. Muscle fatigue as a limiting factor in functional electrical stimulation: a review. Physiother Theory Pract 1989; 5: 83-90.

9 Belanger AY. Neuromuscular electrostimulation in physiotherapy: a critical appraisal of controversial issues. Physiother Theory Pract 1991; 7: 83-89.
10 Pette D, Vrbova G. Neural control of phenotypic expression in mammalian muscle fibres. Muscle Nerve 1985; 8: 676-689.

11 Navarette $R$, Vrbova G. Activity-dependent interactions between motoneurones and muscle: their role in the development of the motor unit. Prog Neurobiol 1993; 41: 93-124.

12 Eerbeek O, Kernell D, Verhey BA. Effects on fast and slow patterns of tonic long-term stimulation on contractile properties of fast muscle in the cat. J Physiol (Lond) 1984; 352: 73-90.

13 Kernell D, Donselaar Y, Eerbeek O. Effects of physiological amounts of high and low rate chronic stimulation on cat's fast muscle. 1. Speed and force related properties. J Neurophysiol 1987; 58: 598-613.

14 Lømo T, Westgaard RH, Dahl HA. Contractile properties of muscle: control by pattern of muscle activity in the rat. Proc $R$ Soc Lond (Biol) 1974; 187: 99-103.

15 Monster AW, Chan HC, O'Conner D. Activity patterns of human skeletal muscles: relation to muscle fibre type composition. Science 1978; 200: 314-317.

16 Rutherford OM, Jones DA. Contractile properties and fatiguability of the human adductor pollicis and first dorsal interosseus: a comparison of the effects of two chronic stimulation patterns. J Neurol Sci 1988; 85: 319-331.

17 Simoneau J A, Pette D. Species-specific effects of chronic nerve stimulation upon tibialis anterior muscle in mouse, rat, guinea pig and rabbit. Pflügers Arch 1988; 412: 86-92.

18 Stein RB et al. Optimal stimulation of paralysed muscle after human spinal cord injury. J Appl Physiol 1992; 72: 1393-1400.

19 Martin TP, Stein RB, Hoeppner PH, Reid DC. Influence of electrical stimulation on the morphological and metabolic properties of paralysed muscle. J Appl Physiol 1992; 72: 1401-1406.

20 Rochester L et al. Influence of electrical stimulation on contractile and histochemical properties of tibialis anterior muscle in paraplegic subjects. J Physiol (Lond) 1992; 452: 278.

21 Dietrichson P, Mellgren SI, Skre H. Muscle biopsy with the percutaneous conchotome technique. J Oslo City Hosp 1980; 30: 73-79.

22 Marsh E, Sale D, McComas AJ, Quinlan J. Influence of joint position on ankle dorsiflexion in humans. J Appl Physiol 1981 51: $160-167$.

23 Barker AT et al. Blocking of transmission of stimulus related electrical interference of inputs of high gain AC preamplifiers used for neurophysiological measurement. J Physiol (Lond) 1987; 391: 4

24 Lambert EH, Underdahl LO, Beckett S, Mederos LO. A study of the ankle jerk in myxoedema. J Endocrinol 1951; 11 1186-1205.

25 Burke RE, Levine DN, Tsairis P, Zajac FE. Physiological types and histochemical profiles in motor units of the cat gastrocnemius. J Physiol (Lond) 1973; 234: 723-748.

26 Edwards RHT, Jones DA, Newham DJ. Low-frequency stimulation and changes in human muscle contractile properties. $J$ Physiol (Lond) 1982; 328: 29-30.

27 Lenman AJR et al. Muscle fatigue in some neurological disorders. Muscle Nerve 1989; 12: 938-942.

28 Armitage P, Berry G. Statistical Methods in Medical Research. 2nd edn. Blackwell: Oxford, 1987.

29 Close R. Dynamic properties of mammalian skeletal muscles Physiol Rev 1972; 52: 129-197.

30 Drachman DB, Johnston DM. Development of a mammalian fast muscle: dynamic and biochemical properties correlated. $J$ Physiol (Lond) 1973; 243: 29-42.

31 Cooper S, Eccles JC. The isometric responses of mammalian muscles. J Physiol (Lond) 1930; 69: 377-385.

32 Grimby L, Broberg C, Krotkiewska T, Krotkiewski M. Muscle fibre composition in patients with traumatic cord lesions. Scand J Rehabil Med 1976; 8: 37-42.

33 Hultman E, Sjöholm H, Sahlin K, Edström L. Human muscle fatigue: physiological mechanisms. In: Porter $\mathrm{R}$ and Whelan $\mathrm{L}$ (eds). Ciba Foundation Symposium 1981; 82: 19-40.

34 Graham SC et al. Enzyme and size profiles in chronically inactive cat soleus muscle fibres. Muscle Nerve 1992; 15: 27-36.

35 Martin TP, Bodine-Fowler S, Edgerton VR. Coordination of electromechanical and metabolic properties of cat soleus motor units. Am J Physiol 1988; 255: 684-693. 
36 Cope TC, Bodine SC, Fournier M, Edgerton VR. Soleus motor units in chronic spinal transected cats: physiological and morphological alterations. J Neurophysiol 1986; 55: 1202-1220.

37 Kaplove K. Reanalysis: impulse activity and fibre type transformation. Muscle Nerve 1987; 10: 375-376.

38 Peckham PH, Mortimer JT, Marsolais EB. Alteration in force and fatiguability of skeletal muscle in quadriplegic humans following exercise induced by chronic electrical stimulation. Clin Orthop 1976; 114: 326-334.

39 Munsat TL. McNeal D, Waters R. Effects of nerve stimulation on human muscle. Arch Neurol 1976; 33: 608-617.

40 Jones DA, Rutherford OM, Parker DF. Physiological changes in skeletal muscle as a result of strength training. $Q J$ Expt Physiol (B) 1989; 74: 233-256.
41 Kernell D, Eerbeek O, Verhey BA, Donselaar Y. Effect of physiological amount of high and low rate chronic stimulation on cat's fast muscle. 2. Endurance related properties. J Neurophysiol 1987; 58: 614-632.

42 Edström L, Grimby L. Effect of exercise on the motor unit. Muscle Nerve 1986; 9: 104-126.

43 Kernell D, Eerbeek O. Recovery after intense chronic stimulation: a physiological study of cat's fast muscle. J Appl Physiol 1991; 70: 1763-1769.

44 Brown JMC, Henriksson J, Salmons S. Restoration of fast muscle characteristics following cessation of chronic stimulation: physiological, histochemical and metabolic changes during slow to fast transformation. Proc $R$ Soc Lond (Biol) 1989; 235: $321-346$. 